\title{
Governamentalidade neoliberal, infâncias e educação: reflexões sobre a nova linguagem da aprendizagem
}

\author{
Jenerton Arlan Schütz" \\ Maria Simone Vione Schwengber
}

\section{Resumo}

O presente artigo tematiza a arte da governamentalidade neoliberal e a relação intrínseca com o controle e a regulação das populações infantis e seus efeitos no campo educacional. Nesse sentido, toma-se como ponto de partida a consideração de que o governo da infância adota por referência três condições: i) a questão do consumo infantil; ii) a questão da concorrência individual; iii) as intervenções educacionais cada vez mais precoces na infância e em sua educação escolarizada. Considera-se que essas condições adquirem uma linguagem específica no campo educacional, que denominamos de a nova linguagem da aprendizagem. Ademais, a nova linguagem da aprendizagem tem facilitado uma nova descrição do processo da educação escolar em termos de uma transação econômica, em que o aluno se torna um (potencial) consumidor, com necessidades e anseios que precisam ser satisfeitos - uma vez que passam a ser o centro do processo educativo. Nesse caso, o professor passa a ser apenas um provedor, um facilitador, um mediador, um orientador a serviço dos aprendentes (clientes). Esse modo de pensar engendra uma nova lógica que faz com que o próprio processo de educação se torne uma mercadoria, uma "coisa" que precisa ser fornecida ou entregue pelo professor e consumida pelo aprendente. Exatamente como exige a lógica neoliberal.

Palavras-chave: Governamentalidade Neoliberal. Infâncias. Linguagem. Educação Escolar.

Doutorando em Educação nas Ciências (Unijui), Mestre em Educação nas Ciências (Unijui), Especialista em Metodologia de Ensino de História (Uniasselvi), Licenciado em História e Sociologia (Uniasselvi) e Licenciado em Pedagogia (Faculdade Campos Elíseos). Atuou como Professor de História e Sociologia no Estado de Santa Catarina (2012-2017). Possui experiência de docência no Ensino Fundamental, Ensino Médio e EJA. Atualmente é Professor de História na Rede Municipal de Ensino de Santo Ângelo/RS. Áreas e autores de investigação: Filosofia da Educação, Modernidade, Condição Humana, Educação Escolar, Infância, Política, Hannah Arendt. E-mail: jenerton.xitz@hotmail.com

** Possui graduação em Educação Física, mestrado em Educação nas Ciências pela Universidade Regional do Noroeste do Estado do Rio Grande do Sul (1997) e doutorado em Educação pela Universidade Federal do Rio Grande do Sul (2006). Atualmente é professora assistente da Universidade Regional do Noroeste do Estado do Rio Grande do Sul. É pesquisadora membro atuante do Grupo de Estudos de Educação e Relações de Gênero (GEERGE/UFRGS/CNPq) (desde 2003) e do grupo do Grupo de Estudo e Pesquisa Paidotibus em (Ijui-CNPq) (2010). Assessoria e consultoria: Consultoria ad hoc para o Ministério da Educação (MEC). Membro da Equipe Avaliadora. Edital MEC Guia de Tecnologias Educacionais Educação Básica (2014-2015). Tem experiência na área de Educação, com ênfase em Educação Física, atuando principalmente nos seguintes temas: educação física, corpo, gênero, educação em saúde e corpo-movimento. E-mail: simone@unijui.edu.br

Data de submissão: abr. 2019 - Data de aceite: jul. 2019 http://dx.doi.org/10.5335/rdes.v15i2.8549 


\section{Introdução}

Há momentos na vida em que a questão de saber se podemos pensar diferentemente do que pensamos, e perceber diferentemente do que vemos, é absolutamente necessária se quisermos continuar de algum modo a olhar e refletir (FOUCAULT, 1984, p. 14).

$\mathrm{O}$ presente artigo tematiza a arte da governamentalidade neoliberal ${ }^{1} \mathrm{e}$, nesse horizonte, o desenvolvimento de estratégias, de mecanismos, de técnicas de controle e regulação das populações infantis. Considerando que as formas de controle e regulação se ajustam também ao modo de governar de outros segmentos da população, tais como aqueles constituídos por sujeitos de outras faixas etárias, como adultos e idosos.

As estratégias, os mecanismos, as técnicas e a regulação das populações infantis estão vinculadas à disseminação de um éthos empresarial, que bjetiva instituir uma infância empreendedora e, desse modo, assumir o governo e o controle específico para essa população. Nesse sentido, assumimos que o governo da infância toma por referência três condições: i) a questão do consumo infantil; ii) a questão da concorrência individual; iii) as intervenções cada vez mais precoces na infância e em sua educação.

A primeira condição - a consumo infantil - justifica-se pelo viés da prevalência capitalista, para que o capitalismo de consumo consiga prevalecer, é fundamental tornar as crianças consumidoras e tornar os consumidores crianças. A segunda condição - concorrência individual - é justificada a partir da importância crucial dada por Foucault (2008a) à governamentalidade neoliberal atuante nas sociedades de controle, em que os mecanismos de concorrência devem constituir o princípio regulador das sociedades reguladas. Por fim, a terceira condição justifica-se pelo fato de as intervenções nas infâncias incidirem cada vez mais cedo, interessa-nos aqui a intervenção no âmbito educacional.

Tais efeitos neoliberais são, cada vez mais presentes no âmbito escolar e, por isso, necessitam ser cartografados. Consideramos que essas condições assumem uma linguagem específica no campo educacional, facilitando uma nova descrição do processo da educação escolar em termos de uma transação neoliberal: na qual o aluno é um potencial consumidor, aquele que possui certas "necessidades" que precisam ser satisfeitas; o professor e a escola são vistos como provedores, que precisam satisfazer as necessidades do aluno; a própria educação se caracteriza como uma mercadoria a ser fornecida ou entregue pelo professor e a ser consumida pelo aluno.

Ponderamos que é essa a ideia que consta por trás de uma concepção de que as escolas e os professores devem possuir flexibilidade, que devem atender e responder às necessidades dos alunos e, 
em muitos casos, a relação deve fundar-se segundo o princípio de que o aluno/ consumidor está sempre com razão, que não deve ser "perturbado". Desse modo, para atrair os alunos, nada mais justo do que criar uma roupagem de que o próprio processo da aprendizagem tem de ser fácil, atraente e emocionante, além de muitos outros elementos mais.

É esse movimento presente atualmente na educação escolar, a saber, da nova relação professor (provedor/facilitador/ mediador/animador) e aluno (consumidor/cliente/protagonista) que tem sido o mote de grande parte das escolas brasileiras e do presente escrito. Outrossim, problematiza-se o que denominamos de a "nova linguagem da aprendizagem ${ }^{2}$, uma vez que essa faz-se presente em vários discursos contemporâneos sobre as infâncias e sua educação.

Portanto, é preciso refletir sobre a infância como uma

[...] prática discursiva e não-discursiva a partir de novas práticas de biopoder, ligadas aos emergentes mecanismos de governamentalidade das populações e dos indivíduos (CRUZ; HILLESHEIM; GUARESHI, 2005, p. 44).

Esse será o movimento empreendido nas próximas páginas.

\section{Governamentalidade neoliberal: perversão e desaparecimento das infâncias}

Ao nos debruçarmos sobre pesquisas que configuram a condição da infância na contemporaneidade, defrontamo-nos com o que se assemelha a uma espécie de sequestro da infância, anunciando a sua morte e sua perversão, o que ocasiona, no desaparecimento da infância.

Esse suposto sequestro ou perversão, morte ou desaparecimento, deve-se não só à comercialização diária da vida humana ou ao declínio das relações entre a infância e cultura, ou entre os adultos e as crianças, mas, especificamente, a partir da comercialização da própria infância, mormente, àquela vinculada pela via do consumismo exacerbado. Barber (2009) reitera que o capitalismo, para sobreviver e prevalecer, precisa tornar as crianças consumidoras e tornar os consumidores crianças, traduzindo-se, grosso modo, num éthos que conduz a essa infantilização de quase todos.

Ainda na esteira do pensamento de Barber (2009), essa infantilização da sociedade aponta, de um lado, para a estupidificação dos bens materiais e dos compradores numa economia que parece produzir mais bens do que as pessoas realmente precisam. E, por outro, para uma atitude de focar nas crianças, uma 
vez que são elas as consumidoras num mercado global em que não há consumidores, relativamente, suficientes. Desse modo, é a infantilização e a sequente estupidificação da sociedade contemporânea que caracteriza a privatização e a despolitização da população em geral.

Podemos considerar que o consumismo exacerbado, a publicidade e o marketing corporativo vêm conseguindo realizar um verdadeiro assalto à infância, o que colabora para a ideia de infância roubada. Nisso, as estratégias de controlar e, literalmente, atingir a população infantil têm efeitos que estão para além da mera quantidade e da qualidade dos produtos e serviços, uma vez que procuram influenciar e afetar nos valores essenciais, a saber, nas escolhas de vida, e, consequentemente, no modo de como buscamos definir a felicidade e como aferimos o nosso valor próprio.

Para Werneck (2007, p. 9-10), esse movimento de governamentalidade neoliberal assume um processo de "desconstrução da infância". Tem-se como resultado, diz ele, que as crianças deixaram de brincar, de sonhar e de (re)inventar seus próprios brinquedos, transformando-se em consumistas vorazes, ao passo que a escola, de tão preocupada em formar alunos competitivos para o mercado, já não lhes oferece o menor prazer nas atividades pedagógicas, e os pais, por sua vez, estariam se tornando incapazes de exercer sua autoridade com firmeza e responsabilidade ${ }^{3}$.
A governamentalidade neoliberal se dirige a todas as populações, entretanto, nossa ênfase será a população infantil, considerando que elas, basicamente, não possuem a maturidade suficiente para discernirem sobre os conteúdos que lhes são veiculados pela publicidade, pelo consumo e pelas demais estratégias de controle e regulação populacional. Outrossim, as crianças estão incapacitadas de se informar sobre os mecanismos e, portanto, julgarem o que lhes é ou não conveniente, a fim de que sejam capazes de tomar decisões coerentes em suas vidas.

Nesse sentido, podemos considerar que esta governamentalidade neoliberal se baseia numa racionalidade fundada num exercício econômico, menos dispendioso e mais produtivo do poder que compõe uma maquinaria de governo que envolve o conhecimento da coisa a ser governada e o desenvolvimento de estratégias de intervenção (FERREIRA, 2013). Almeja-se, grosso modo, a obtenção de sucesso no disciplinamento dos corpos infantis, com o intuito de, quando estes forem adultos, as coerções já não precisarem ser tão mandatórias e severas.

Esse disciplinamento são operações sobre os corpos das crianças, as suas almas, seu próprio pensamento, sua conduta, e isso de tal modo a transformarem-se a eles próprios, a modificarem-se, ou a agirem num certo estado de perfeição, de felicidade, de pureza, de 
poder sobrenatural e assim por diante (FOUCAULT, 1993). Nessa perspectiva, o não investimento na infância seria, segundo a governamentalidade neoliberal, desperdiçar uma grande chance de governamento.

Nessa direção, a disseminação de uma cultura empreendedora neoliberal pode ser pensada a partir de processos, mecanismos e estratégias de subjetivação, regulação e controle dirigidas às populações (infantis, adultas, idosas...), com vistas à programar os modos de agir, pensar e sentir dos indivíduos, além do modo de como esses se situam diante de si mesmos, do modo da vida que levam e no mundo em que vivem.

Tais processos, mecanismos e estratégias de subjetivação, regulação e controle fazem dos princípios econômicos (mercadológicos) os princípios que devem normatizar toda a vida na sociedade, traduzindo-se naquilo que denominamos de sociedade de consumo ${ }^{4}$, fazendo com que os indivíduos estabeleçam, cada vez mais, relações de concorrência entre si, tornando-se, também, numa sociedade de empresa. Nas palavras de Foucault (2008b, p. 200-201),

A sociedade regulada com base no mercado em que pensam os neoliberais é uma sociedade na qual o que deve constituir o princípio regulador não é tanto a troca de mercadorias quanto os mecanismos de concorrência. São esses mecanismos que devem ter o máximo de superfície e de espessura possível, que também devem ocupar o maior volume possível na sociedade. Vale dizer que o que se procura obter não é uma sociedade submetida ao efeito-mercadoria, é uma sociedade submetida à dinâmica concorrencial. Não uma sociedade de supermercado - uma sociedade empresarial. O homo oeconomicus que se quer reconstituir não é o homem da troca, não é o homem consumidor, é o homem da empresa e da produção.

Essa relação da sociedade de consumo com a sociedade de empresa faz surgir o que denominamos de indivíduo micro-empresa - uma espécie de "Você $S / A$ " - e da produção, que podemos também denominar de empreendedor. Na medida em que agem e fazem como qualquer empresa, sob a lógica dos investimentos, da eficácia, da eficiência, da competitividade, da inovação, logo, suas relações sociais, seus valores e comportamentos são determinados por relações que são, de modo eminente, concorrenciais.

Nesses termos, o outro não pode assumir o lugar de outridade/alteridade ${ }^{5}$, pois a relação que se estabelece é de que o outro é, virtualmente, um concorrente, um obstáculo a ser superado, batido e, excepcionalmente, descartado. O outro é um empreendedor que concorre comigo e com os demais, eis ser fundamental que o empreendedor (sujeito) conte consigo mesmo para enfrentar os desafios diários. Não é à toa que o verdadeiro empreendedor é aquele capaz de aprender sozinho, e nesse movimento concordamos com Bauman (2008), em que o problema não é propriamente o de consumir mercadorias, mas em tratar o outro como tal. 
Para Dolabella (2003, p. 16):

Na lida aprendi que todos nascemos empreendedores e que, se deixamos de sê-lo mais tarde, isso se deve à exposição a valores antiempreendedores na educação, nas relações sociais, no 'figurino cultural' conservador a que somos submetidos. Lidar com crianças, portanto, é lidar com autênticos empreendedores ainda não contaminados por esses valores.

Como a criança é, naturalmente, um empreendedor, porque não partir de uma educação que lhe permita desenvolver, desde a primeira infância, suas potencialidades, habilidades e competências, investindo em seu capital humano, realizando seus sonhos e atingindo seu pedido de felicidade? Trata-se de um retorno romântico ao Emílio de Rousseau, no qual é fundamental tomar as crianças como guias, já que são empreendedoras natas e não se deve desconsiderar seus impulsos e emoções "naturais".

E, nessa esteira de pensamento, chegam os gritos em favor da libertação da criança, por intermédio de sua educação e conscientização. Como se, de repente, se dessem conta de que nunca se teria escutado as crianças, de que nunca se tinha levado a sério o que elas têm a nos dizer. Por isso, encontramo-nos na nova palavra de ordem: "é preciso dar voz e vez às crianças", a fim de saber o que elas sentem, pensam, querem e necessitam.

Contudo, esse modo de pensar nos remete à crítica empreendida aos sistemas educacionais que não possibilitam experiências singulares, inovadoras e, principalmente, não se baseiam nos interesses e nas necessidades empreendedoras emitidas pelas próprias crianças. Uma vez que a intervenção nas subjetividades significa satisfazer as reivindicações libertárias, autonomistas, hedonistas, existenciais, imaginativas, a governamentalidade neoliberal enfatiza em reivindicar um trabalho mais interessante, criativo, imaginativo, simétrico, fácil, prazeroso, moderno, entre outros aspectos atraentes.

Entretanto, são essas condições que, ao nosso entender, fazem surgir um empobrecimento nas relações de sociabilidade entre aqueles que ensinam e aqueles que aprendem, bem como um empobrecimento do próprio processo de aprendizagem, na medida em que esta é recodificada e (re)operacionalizada por uma lógica instrumental que a reduz ao domínio de certas competências valorizadas pelo éthos empresarial.

Nesse contexto, temos a oferta e a disponibilização de inúmeras informações e conhecimentos sobre os indivíduos que alimentam uma pedagogia da autorrealização, do autodidatismo, do protagonismo, da autonomia, da liberdade, do aluno como centro do processo, etc. Entretanto, é muito provável que aquilo que se denomina de "protagonismo juvenil" não passe de uma adesão impensada do aluno ao princípio do prazer e à lei do mínimo esforço, que resistem a qualquer argumento 
sobre necessidades, valores e exigências; ou de uma escolha sugerida (para não dizer imposta) pela lógica mercadológica.

Portanto, é nesse contexto da governamentalidade neoliberal e de seus esforços na regulação e no controle das populações, aqui, em especial, a população infantil, que fazem surgir as urgências em torno do sujeito infantil. No entanto, tais urgências são regidas pelo mercado, pelo consumo, enfim, pela governamentalidade neoliberal, acarretando, por um lado, uma espécie de sequestro e perversão da infância e, por outro, o seu desaparecimento.

Consideramos que é nesse momento - de governamentalidade neoliberal e da soma de todos os seus mecanismos, estratégias e políticas de controle e regulação - em que temos a substituição de uma linguagem da educação por uma linguagem da aprendizagem, e o movimento que doravante assumimos é o de problematizar essa linguagem e demonstrar as tensões e os limites dessa linguagem para o âmbito educacional.

\section{A nova roupagem da linguagem na educação escolar}

Por que a linguagem é importante para a educação escolar? Se considerarmos a linguagem apenas como uma forma de descrever a realidade, não necessitaríamos dizer muito sobre essa questão. Nesse caso, a educação escolar simplesmente "é" e a linguagem simplesmente descreve "o que é". Contudo, a descrição é apenas uma das funções da linguagem, sendo ela, inclusive, uma função problemática, uma vez que a linguagem não é apenas um espelho da realidade, pois pode ser também uma prática, algo que fazemos.

Nas palavras de Foucault (2007), sabemos que as práticas linguísticas e discursivas delineiam e constituem aquilo que pode ser visto, dito, conhecido, pensado e feito. Do mesmo modo, a linguagem pode tornar possíveis alguns modos de dizer e fazer e tornar outras maneiras de dizer e fazer difíceis e às vezes até impossíveis. Eis um dos motivos de a linguagem importar para a educação escolar, uma vez que a linguagem (ou as linguagens) existente para a educação escolar influencia em grande medida o que pode ser dito e feito, e também aquilo que não pode ser dito e feito.

A partir de uma intervenção da governamentalidade neoliberal, consideramos que a linguagem existente para os educadores tem passado por uma transformação nas últimas décadas. Ponderamos que a linguagem da educação tem sido, em grande parte, substituída por uma linguagem da aprendizagem, embora que com essa "nova linguagem da aprendizagem" tenha se tornado possível expressar algumas noções e compreensões que eram um tanto difíceis de articular por meio da 
linguagem da educação, outros aspectos de nossa compreensão do que a educação escolar é ou deveria ser tornaram-se mais difíceis de serem articuladas.

Por isso, reiteramos que algo se perdeu na mudança da linguagem da educação para a linguagem da aprendizagem. Uma das alterações mais notáveis que ocorreram na teoria e prática da educação nos últimos anos foi a ascensão do conceito de "aprendizagem" e o subsequente declínio do conceito de "educação". Ensinar passa a ser definido como facilitar a aprendizagem, assim como a educação escolar é frequentemente descrita como propiciadora de oportunidades ou experiências de aprendizagem.

Para Biesta (2017), a aprendizagem tornou-se um conceito favorito em vários documentos nacionais e internacionais ${ }^{6}$, para ele, colocar os aprendentes e a aprendizagem no centro do processo educativo e de métodos e processos de treinamento não é absolutamente uma ideia nova. Pois, na prática, a estrutura estabelecida das práticas pedagógicas na maioria dos contextos formais tem privilegiado o ensino em vez da aprendizagem.

Contudo, numa sociedade com um conhecimento de alta tecnologia, esse tipo de ensino e aprendizagem perde o sentido e a eficácia, pois os aprendentes devem se tornar proativos (protagonistas) e mais autônomos, e os professores se tornam acompanhantes, facilitadores, apoiadores, mediadores, orientadores a serviço dos esforços dos aprendentes para acessar, utilizar e, finalmente, criar o conhecimento. Qual seria o problema da linguagem da aprendizagem? Existe uma razão para ser contra a "aprendizagem"?

Consideramos que o principal problema com a nova linguagem da aprendizagem é que ela tem facilitado uma nova descrição do processo da educação em termos de uma transação econômica, isto é, uma transação em que o aluno, agora denominado de aprendente, torna-se um (potencial) consumidor, alguém que tem necessidades, desejos e sonhos que precisam ser satisfeitos. Esse modo de pensar injeta uma nova lógica que enfatiza, praticamente, apenas no usuário ou no consumidor do serviço educacional. Não seria, pois, o nome mais adequado para este consumidor do que o de "o aprendente"?

Nesse sentido, o professor e a instituição escolar são vistos como os provedores, isto é, como aqueles que visam satisfazer as necessidades do aprendente e a própria educação passa a ser vista como uma mercadoria, uma "coisa" que precisa ser fornecida ou entregue pelo professor ou pela instituição escolar e a ser consumida pelo aprendente.

Essa é a lógica que está por trás da noção de que as instituições educacionais e os próprios professores sejam flexíveis, que necessitam responder às necessidades dos aprendentes, operando segundo o princípio de que o aprendente/consumidor está sempre com razão. Nota-se 
claramente que, na nova linguagem da aprendizagem, você não precisa ter nenhuma experiência, em que a aprendizagem não deve ser perturbadora, além da "equipe pedagógica" estar sempre a postos para ajudar os aprendentes. Esse modo de pensar propõe que cada aluno construa seu próprio conhecimento a partir de experiências próprias. Cabe ao 'professor facilitador' envolver o aluno enquanto protagonista de sua aprendizagem e deixar de ser apenas uma fonte de informação e conhecimento.

Além disso, a linguagem da aprendizagem segue também a lógica que exige dos educadores e das instituições escolares uma certa "prestação de contas", pois o que constitui, em última análise, a relação entre aprendente/consumidor/cliente e o educador/provedor/facilitador são os pagamentos que os aprendentes realizam quer diretamente, ou, como no caso da educação financiada pelo Estado, por meio de impostos (BIESTA, 2017). Em suma, o professor deve se lembrar de que na realidade não se ensina, ajuda o aluno a aprender.

Em consequência, a aprendizagem tornou-se muito mais central na compreensão do processo educacional. Noções como "servir de andaime" têm ajudado a fornecer uma perspectiva em que o ensino pode ser facilmente redefinido como apoio à facilitação para a aprendizagem. Com isso, assume-se que o conhecimento e a compreensão são ativamente construções do aprendente.
Nessa direção, Burke (2003, p. 49) considera que a aprendizagem "é um processo construtivo interno do aluno e não um processo depositário de fora para dentro". Não obstante, nas palavras de Saviani (2007, p. 429),

[...] o importante é aprender a aprender, isto é, aprender a estudar, a buscar conhecimentos, a lidar com situações novas. E o papel do professor deixa de ser o daquele que ensina para ser o de auxiliar o aluno em seu próprio processo de aprendizagem.

Não raras vezes, ouve-se o discurso de que o professor não é mais o detentor do saber.

Não diferente, conforme Lima (2000), o papel do professor não é a de explicar, e sim a de propor atividades que levem o aluno à compreensão, não é necessário ensinar nada às crianças, elas precisam apenas de clima estimulador que possibilite a estruturação de seu comportamento. Em consonância, para Schütz (2017a, p. 50), nesta perspectiva

[...] o aluno seria o autor principal da construção do conhecimento, isto é, por sua própria capacidade de raciocínio o aluno estaria apto para construir o conhecimento, desenvolver suas habilidades e resolver seus problemas. Resta ao professor se tornar um sujeito de vários adjetivos: um animador, um apresentador, um simples colaborador ou corriqueiramente denominado de facilitador de todo processo. Recebe os adjetivos pois nessa modalidade de ensino e aprendizagem o que se deve levar em consideração é o aluno, seu desenvolvimento, sua aprendizagem, estando todo o processo de aprendizagem centrado no aluno e no seu potencial de habilidades. 
Já para Lajonquière (2002), tal perspectiva provoca no professor o deslocamento da posição de sujeito suposto do saber, abolindo sua autoridade de mestre e, consequentemente a renúncia do ato educativo, alimentando diversas formas de manifestações de camaradagem simpática como meio de estabelecer supostamente uma melhoria na relação professor-aluno.

Desse ponto de vista, a eficácia das ações educativas está determinada pelo seu poder de fazer passar do possível ao real. E a reflexão pedagógica se faz em termos de meios, de fins e de processos. A educação é, em suma, a obra de um pensamento calculador e de uma ação técnica, em que se trata de conseguir um produto real mediante a intervenção calculada num processo concebido como um campo de possibilidades. Uma prática técnica, definitivamente, em que o resultado deve ser produzir segundo o que foi previsto antes de iniciar (LARROSA, 1999, p. 193).

Assim como nos modelos de mercado, supõe-se que os consumidores sabem do que necessitam, e os produtores oferecem melhor preço e mais "qualidade" para satisfazê-los. Logo, pensar na educação escolar como uma transação econômica, como um modo de satisfazer as necessidades do aprendente - algo que se tornou viável a partir da nova linguagem da aprendizagem - é, nesse contexto, antes de mais nada problemático, uma vez que se compreende mal o papel do aprendente e o papel do professor na relação educacional.
Consideramos que na perspectiva da "nova linguagem da aprendizagem" a relação educacional é composta por uma simetria entre professor e aluno, dito de outra forma, há uma igualização e um nivelamento das relações intergeracionais (crianças e adultos, alunos e professores). Desse modo, como podemos

[...] conceber a relação educativa numa sociedade e numa cultura atravessadas por uma fantástica dinâmica de igualização que faz aparecer o outro, qualquer outro, como um outro eu-mesmo, portanto como um igual? (RENAUT, 2002, p. 22).

Tal ponderação é fundamental, pois leva a crer que se esquece de uma das razões principais de se engajar na educação, a saber, a de "[...] descobrir o que realmente se deseja ou precisa" (BIESTA, 2017, p. 41). Esquece-se, também, de que os profissionais da educação têm um papel crucial a desempenhar no processo da definição das necessidades, porque uma parte importante de sua competência profissional reside nesse ponto; um papel que precisamente os distingue dos vendedores e provedores, cuja única tarefa é entregar as mercadorias ao cliente (BIESTA, 2017).

Há, portanto, duas objeções contra a nova linguagem da aprendizagem ou, contra esse modo de pensar operante que tornou possível a produção de uma nova linguagem. Um problema é que a nova linguagem da aprendizagem passa a introduzir uma compreensão econômica 
no processo da educação (governamentalidade neoliberal), na qual, o denominado aprendente supostamente sabe o que ele deseja e na qual o provedor se apresenta como um simples sujeito que satisfaz as necessidades do aprendente - satisfaz o cliente, para ser mais claro. E, conforme já supracitado, esta perspectiva interpreta mal as relações educacionais.

Outro problema que surge com a nova linguagem da aprendizagem é que ela complica no modo de propor questões sobre o conteúdo e o objetivo da educação escolar, uma vez que os conteúdos e os objetivos devem ser aqueles formulados na perspectiva do que o cliente e o mercado desejam, impossibilitando um debate democrático na renovação da sociedade educacional.

Assim, despojada de qualquer sentido intrínseco, a escola fica à mercê da ilusão do "pathos do novo". Ilusão de que se nutrem as modernas teorias educacionais - com frequência constituídas de uma impressionante miscelânea de bom senso e absurdo - e cujo propósito é revolucionar todo o sistema educacional (SCHÜTZ, 2017b).

Por fim, acreditamos que é preciso ter cautela ao se fazer uso da linguagem da aprendizagem, não só porque esse uso pode vir a solapar nossa própria função enquanto professores, mas também porque pode desgastar ou impossibilitar uma discussão aberta e democrática sobre os conteúdos e objetivos da educação escolar. Não diferente, torna-se plausível compreender que a nova linguagem da aprendizagem se ajusta à estrutura do pensamento neoliberal, inserindo-se na trama da governamentalidade.

\section{Considerações finais}

Empreendemos um movimento cauteloso, audacioso e necessário. Nesse jogo de relações, tensões, limites e discursividades, destacamos a criação de inúmeros meios de intervenção nas diferentes áreas: vida familiar, saúde, educação, instituições etc., configurando-se num governamento dos homens, via governo das crianças. Um movimento entre governo e autogoverno das infâncias.

Instaura-se, nesse contexto, a veridição sobre o infantil, uma discursividade alicerçada no saber-poder-ser, que produz subjetividades que anunciam as crianças como autônomas, protagonistas, criativas, competentes, críticas, livres, empreendedoras e felizes. Desse modo, intensifica-se e otimiza-se nos discursos e práticas pedagógicas a necessidade de se dar voz e vez às crianças, a fim de saber o que elas sentem, pensam, querem e necessitam.

Esse modo de pensar refere-se à crítica empreendida aos sistemas educacionais que são considerados como impossibilitadores de experiências singulares, inovadoras e, principalmente, por não se basearem nos interesses e necessidades 
empreendedoras emitidas pelas próprias crianças. Porque, então, não se partir de práticas educacionais que permitam que as crianças desenvolvam, desde a primeira infância, suas potencialidades, habilidades e competências, investindo em seu capital humano, realizando seus sonhos e atingindo o seu pedido de felicidade?

Nessa perspectiva, notamos que há inúmeras urgências em torno do sujeito infantil, contudo, é preciso atentar que tais urgências são regidas pelo mercado, pelo consumo, enfim, pelo neoliberalismo, acarretando, por um lado, uma espécie de sequestro das infâncias e, por outro, o seu desaparecimento. Com isso, os mecanismos e estratégias de subjetivação, regulação e controle fazem dos princípios econômicos (mercadológicos) os princípios que devem estruturar toda a sociedade. É nesse contexto que podemos considerar que o consumismo exacerbado, a publicidade e o marketing corporativo vêm conseguindo realizar um verdadeiro assalto/sequestro às infâncias.

A partir da governamentalidade neoliberal, consideramos que a linguagem existente para os educadores tem passado por uma transformação, a linguagem da educação tem sido, em grande parte, substituída por uma linguagem da aprendizagem. Embora com essa "nova linguagem da aprendizagem" tenha se tornado possível expressar algumas noções e compreensões que eram um tanto difíceis de articular por meio da linguagem da educação, outros aspectos de nossa compreensão do que a educação escolar é, ou deveria ser, tornaram-se mais difíceis de serem articulados.

E nessa lógica, a linguagem da aprendizagem passa a assumir a linguagem da educação, vinda com uma roupagem que visa empreender esforços facilitadores em torno de uma nova descrição do processo educativo em termos de uma transação neoliberal, de uma governamentalidade neoliberal. $\mathrm{O}$ professor passa a ser um facilitador, um animador, um provedor, já o aluno passa a ser um aprendente, um consumidor, um cliente, um protagonista, com autonomia o suficiente para ser, inclusive, o centro de todo processo educativo.

Por isso, nada mais justo do que ouvir e satisfazer as suas necessidades do aprendente, afinal, é isso que o fará feliz e, nada de perturbações e/ou dificuldades, eis o motivo de o próprio processo da aprendizagem exigir um caráter fácil, atraente, prazeroso, emocionante, além de muitas outras coisas mais. Trata-se de uma educação que possa servir ao mercado, aos projetos pessoais, em suma, almeja-se tornar a escola mais aprazível e mais conformada com os desejos dos aprendentes.

Lembrando que são a flexibilidade, a autonomia, a criatividade, a agilidade e a abertura para as novas situações que marcam as demandas do mercado, pois, 
são estas as características que possibilitam tornar $\mathrm{o}$ aprendente em alguém que aprendeu a aprender e que continuará eternamente aprendendo, tornando-se alguém apto a enfrentar as condições precárias e, geralmente, provisórias de trabalho, mudando frequentemente os rumos de sua vida e/ou carreira e conseguindo se manter (não necessariamente firme e/ou estável) no mercado.

Ademais, se entendermos que a educação escolar consegue e pode oferecer mais do que um mero treinamento em determinadas habilidades e a aquisição de certos conhecimentos, é possível constatar sua crescente ausência. É notável que, num momento em que (com)partilhamos cada vez menos valores, parece não fazer sentido ensinar aos mais novos princípios que poderão vir a orientá-los em suas decisões e seus julgamentos no futuro. A suposta liberdade de cada indivíduo para fazer suas próprias escolhas parece isentar a educação de sua responsabilidade ética e política.

No fim, a tirinha da Mafalda é que nos resta!
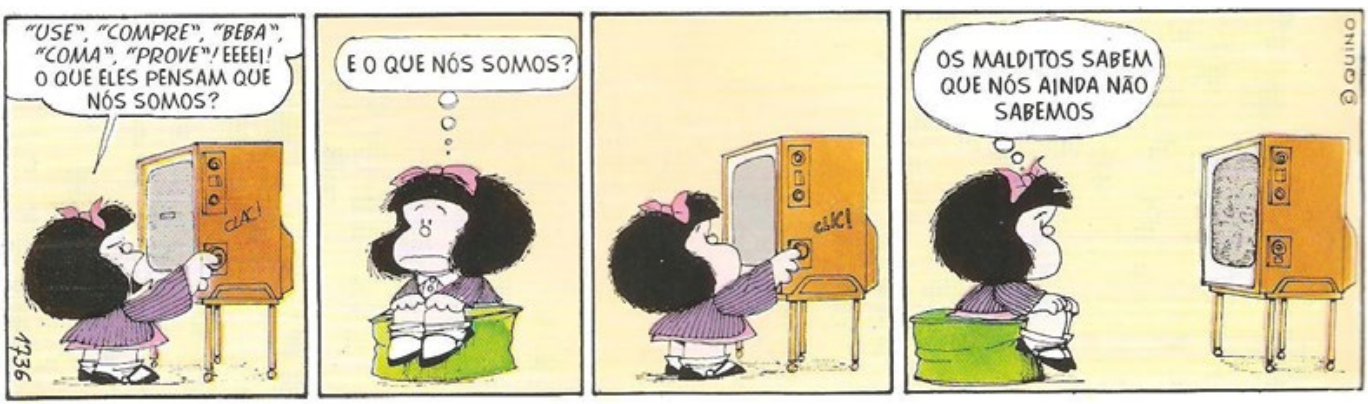

Fonte: Quino (2003, p. 372, tira 5).

\section{Neoliberal governmentality, childhood and education: reflections about the new language of learning}

\section{Abstract}

This article discusses the art of neoliberal governmentality and the intrinsic relation with the control and regulation of children 's populations and their effects in the educational field. In this sense, we take as a starting point the consideration that the government of childhood adopts by reference three conditions: i) the issue of child consumption; (ii) the issue of individual competition; (iii) increasingly early educational interventions in childhood and schooling. It is considered that these conditions acquire a specific language in the educational field, which we call the new language of learning. In addition, the new language of learning has facilitated a new description of the school education process in terms of an economic transaction, in which the stu- 
dent becomes a (potential) consumer, with needs and desires that need to be satisfied - once they become be the center of the educational process. In this case, the teacher becomes only a provider, a facilitator, a mediator, a mentor at the service of the learners (clients). This way of thinking engenders a new logic that makes the education process itself a commodity, a "thing" that needs to be supplied or delivered by the teacher and consumed by the learner. Just as neoliberal logic demands.

Keywords: Neoliberal governmentality. Childhood. Language. Schooling.

\section{Notas}

O modus operandi da governamentalidade neoliberal tem na liberdade uma concepção articuladora no processo de veridição, produzida como algo a se buscar, querer, isto é, um objeto de consumo. Por isso, não investir na infância seria um terrível desperdício.

2 A noção de aprendizagem que aqui assumimos refere-se à aprendizagem enquanto aquisição, na busca de obter mais e mais, querendo mostrar quem você é e em que posição está. Dito de outro modo, o que vemos é uma busca incessante pelas diferentes formas de aprendizagem, dentro e fora das instituições educacionais, para citar algumas: academias, manuais de autoajuda, palestras motivacionais, coaching, internet, vídeos etc, trata-se de uma explosão silenciosa da aprendizagem, muito mais individualista, uma luta consigo mesmo, com seu corpo, suas relações ou sua identidade.

3 Não raras vezes ocorre que as crianças se "autorizam" sobre os pais que perderam as referências, o que demonstra a dificuldade dos pais em sustentar sua posição de autoridade responsável perante as crianças, além de apresentar a realidade de vários pais que não conseguem impor limites a seus filhos porque estes "não deixam", levantando a suspeita de, afinal, "quem educa quem"?

4 Baudrillard (2008), e diversos outros autores, como Bauman (1999), Featherstone (1995) e
Lipovetsky (1989) consideram que a sociedade pós-moderna é uma sociedade de consumo.

5 Significa reconhecer-se no outro (e com o outro), mesmo que a princípio existem diferenças físicas, psíquicas e culturais. Por esse motivo, o eu na sua forma individual só pode existir através de um contato com o Outro, com a diferença.

6 Para citar alguns: o documento da "Aprendizagem de vida inteira para todos" da Organização para Cooperação e Desenvolvimento Econômico (OCDE), a "Declaração Mundial sobre Educação para Todos: satisfação das necessidades básicas de aprendizagem" da Unesco, entre os documentos brasileiros podemos citar os Parâmetros Curriculares Nacionais (PCNs).

7 Pathos do novo é um conceito utilizado por Arendt (2013) para denominar o afã das sociedades modernas pelo novo e o consequente rechaço ao velho (tradição). Nessa direção, o novo e sua novidade são revestidos de positividade e entendidos como avanço, enquanto os saberes da tradição são considerados ultrapassados e inúteis.

\section{Referências}

ARENDT, H. Entre o passado e o futuro. Tradução de Mauro W. Barbosa. 7. ed. São Paulo: Perspectiva, 2013.

BARBER, Benjamin. Consumido: como o mercado corrompe crianças, infantiliza adultos e engole cidadãos. Rio de Janeiro: Record, 2009.

BAUDRILLARD, J. A sociedade de consumo. Portugal: Edições 70, 2008.

BAUMAN, Zygmunt. Globalização: as consequências humanas. Rio de Janeiro: Jorge Zahar, 1999.

BAUMAN, Zygmunt. Vida para consumo: a transformação das pessoas em mercadoria. Trad. de Carlos A. Medeiros. Rio de Janeiro: Jorge Zahar Ed., 2008.

BIESTA, Gert. Para além da aprendizagem: educação democrática para um futuro humano. Trad. de Rosaura Eichenberg. 1. ed. Belo Horizonte: Autêntica Editora, 2017. (Coleção Educação: Experiência e Sentido). 
BURKE, T. J. O professor revolucionário: da pré-escola à universidade. Petrópolis, RJ: Vozes, 2003.

CRUZ, Lílian R. da; HILLESHEIM, Betina; GUARESCHI, Neuza M. Infância e políticas públicas: um olhar sobre as práticas psi. Psicologia \& Sociedade, v. 17, n. 3, p. 42-49, set-dez, 2005.

DOLABELLA, Fernando. Pedagogia empreendedora. São Paulo: Ed. De Cultura, 2003.

FEATHERSTONE, M. Cultura de consumo e pós-modernismo. São Paulo: Studio Nobel, 1995.

FERREIRA, Patrícia Helena. Tramas e grades: inventários sobre a criança na educação infantil. Tese de Doutorado. Faculdade de Educação, Programa de Pós-Graduação em Educação, Universidade de São Paulo (USP), São Paulo, 2013.

FOUCAULT, Michel. História da Sexualidade II: o uso dos prazeres. Rio de Janeiro: Graal, 1984.

FOUCAULT, Michel. Segurança, território, população. São Paulo: Martins Fontes, 2008a.

FOUCAULT, Michel. O nascimento da biopolítica. Trad. de Eduardo Brandão. São Paulo: Martins Fontes, 2008b.

FOUCAULT, Michel. Verdade e subjectividade. Revista de Comunicação e Linguagem. n. 19. Lisboa: Edições Cosmos, p. 203-223, 1993.

FOUCAULT, Michel. As palavras e as coisas: uma arqueologia das ciências humanas. Tradução de Salma Tannus Muchail. 9. ed. São Paulo: Martins Fontes, 2007. (Coleção Tópicos).

LAJONQUIÈRE, Leandro de. Infância e Ilusão (Psico) pedagógica: Escritos de psicanálise e educação 3.ed. Petrópolis: vozes, 2002.

LARROSA, Jorge. O enigma da infância ou o que vai do impossível ao verdadeiro. In: LARROSA, Jorge. Pedagogia profana: danças, piruetas e mascaradas. Trad. Alfredo Veiga-Neto. Belo Horizonte: Autêntica, 1999.
LIMA, L. de O. Piaget: sugestões aos educadores. Petrópolis, RJ: Vozes, 2000.

LIPOVETSKY, Gilles. O Império do Efêmero: A moda e seu destino nas sociedades modernas. São Paulo: Companhia das Letras, 1989.

QUINO, J. L. Toda Mafalda. São Paulo: Martins Fontes, 2003.

RENAUT, A. A Libertação das crianças: a era da criança cidadão. Lisboa: Instituto Piaget, 2002.

SAVIANI, Dermeval. História das ideias pedagógicas no Brasil. São Paulo: Autores Associados, 2007.

SCHÜTZ, J. A. Consequências de uma educação facilitadora. Revista Di@logus, Cruz Alta, v.6, n.2, p. 44-63, maio/ago. 2017a.

SCHÜTZ, J. A. Autonomia e mundo infantil: reflexões à luz de Hannah Arendt. Cadernos da Fucamp, v. 16, n. 26, p. 87-107, 2017.

WERNECK, Hamilton. O que é a escola empreendedora. Petrópolis (RJ): DP et Alii Editora, 2007. 